0

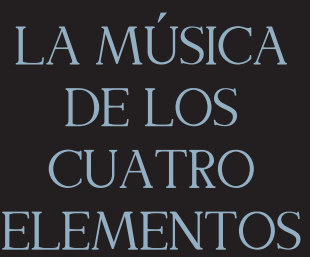

La ensoñación poética nos ofrece el mundo de los mundos. Ella es la puerta de entrada a un mundo hermoso, a mundos hermosos. Ofrece al yo un no-yo que es el bien del yo: mi propio no-yo mío. Es ese no-yo mío lo que encanta al yo del soñador y que los poetas saben hacernos compartir. Para mi yo soñador, es ese no-yo mío lo que me permite vivir con la confianza para estar en el mundo (Bachelard, G., 2011, p. 12).

Los cuatro elementos (2005), concierto para flauta, coro infantil y pequeña percusión, dedicado a

Pierre-Yves Artaud. La obra sugiere en cuatro partes distintas Tierra, Agua, Fuego y Aire. En una forma ritual, con momentos de encantamiento, es un himno a la naturaleza (Lacaze, S. 2005. p. 2).

Naturaleza que no hace diferencia alguna entre los seres, para la cual el día y la noche son equivalentes. Actúa de tal manera que yo considere los hombres como insectos, los insectos como hombres y el conjunto del Todo como Nada.... . Dame la libertad del viento (Grenier, J.1948 p. 73.).

Acaso no debería buscarse también la explicación en la supervivencia arquetípica de un drone en el seno de la conciencia musical más "cultivada"? No tenemos que elegir entre cultura e incultura allí donde es la naturaleza la que habla! (Charles, D. (2001), p. 103.). 


\title{
LA MÚSICA DE LOS CUATRO ELEMENTOS
}

\author{
Geneviève Paule Mathon
}

Traducción del Francés: Alberto Leongómez H.

I. Hay siempre un punto de partida para toda cosa humana; también existe siempre ese cuestionamiento de los orígenes que conduce a la obra de arte, por poco que ella lo quiera, a consentir a esta fragilidad, durante el tiempo de su fabricación. Cuestionamiento que no deja de ser vano, puesto que se conoce su salida, pero que compromete en un camino, un sendero paciente, obstinado, amante. Las obras de Sophie Lacaze se experimentan en la confrontación con otras obras, aún las suyas, que uno observa, escucha, interroga, prolonga, estirándose hasta producir la ilusión de que nada puede perderse, extraviarse u olvidarse. Para ello es necesario elegir un objeto (de deseo) y comentarlo, comentar los comentarios que ha suscitado. Entendamos por comentario el hecho de dar una forma singular al aura de una obra, a la emoción que ella nos despierta. Este proceso de visitación, de rememoración, implica aquel de una re-escritura. Gesto propio de Sophie Lacaze, puesto que afecta sus obras, que ella no ha dejado de retomar, de las que se desprende y vuelve a retomar, para inventar nuevas versiones. Reescribir es siempre precisar un gesto, discernir una vez más una intuición, y es también completarla, aplazarla, desviarla, curvarla, traicionarla, sin acabarla jamás: eso sería firmar su sentencia de muerte. Si el compositor se encuentra en una dinámica cuyo torrente lleva objetos visuales, táctiles o sonoros, el escucha se mueve en sentido inverso: hermenéutica de una escucha, de un saber, de un proceso que se reconstruye mediante una puesta en abismo de los objetos, que son ordenados de nuevo para volver a encontrar finalmente el objeto primero, original. Podrían ser así descritas las músicas de Sophie Lacaze. Los Cuatro Elementos es una obra que parece sin embargo escapar a este proceso de una memoria que se hurga. Aquí encontramos cuatro imágenes yuxtapuestas sobre un mismo plano, lado a lado. Intentemos una descripción.

La obra se inicia con Tierra, que instala un ostinato rítmico, simple, fundado sobre un sistema de acentuaciones, por medio de alturas (percusiones sobre tres alturas), de juegos de choques, de sílabas (susurradas y luego habladas) y finalmente, de los sonidos de la flauta. Este fenómeno de saturación paulatina, como un lienzo que se ilumina poco a poco, las campanas que se suman, nos conduce a la tercera parte $(1 / 3)$ de la obra, su punto de clímax (ff, compás 34, letra B). Otros elementos (imitación de animales por la percusión) intervienen, al mismo tiempo que la curva se invierte: el caudal sonoro se atenúa poco a poco -entra ahora en la penumbrahasta su extinción. Se opera un ligero incremento de la materia, en la fase descendente (compases 55 a 65), con la aparición de sonidos eólicos. Progresiva aparición de la imagen de una lejanía no identificable / máxima coloración / desaparición progresiva, por intermitencias, de la imagen.

"El rojo se enrojece", "el violoncelo se violonceliza" son expresiones recientemente empleadas por Emmanuel Levinas para describir el aspecto no narrativo, no teleológico, de esta primera pieza. Está escrita en 89 compases, número primordial.

La segunda pieza Agua (Lento) instala un nuevo ostinato construido sobre cinco alturas: un B.A.C.H. transportado (re-do sostenido-mi-re sostenido), al cual se le añade una altura (fa) (= cromatismo invertido); este ostinato de 3 compases se presenta en canon (de un compás). El sistema de acentuación se ve realzado por el enunciado silábico de fragmentos poéticos: "el agua es gris y azul", "alargado como un brazo de mar", "vi-bra-ciones divinas de los mares verdes" (Rimbaud); "se formaban manteles de agua, azules", "entre los muelles verde / rosa" (Baudelaire); "cuán suave es el sonido de las olas, sobre las cuales se desliza un barco" (Príncipe Shotoku). Estos 17 compases (número primordial) ceden para dar lugar a una peroración estática, no mesurada, alrededor de la nota re.

La tercera pieza Fuego (Rápido) se concentra en el juego de la flauta en $d o$, monodia que no deja de ganar en densidad, amplitud e intensidad. Próxima por ello a una técnica de "acumulación" a la Ligeti (Lux aeterna, por ejemplo), las notas se suman, se sobre-imprimen, desplegándose desde un centro: el do sostenido; las voces acentúan este proceso acumulativo y de ascensión succionando los reservorios fonemáticos para crear un rumor que poco a poco se precisa por el enunciado y el entrechoque de palabras: fuego, luz, brasas, llama, expulsión, amarillo, danza, explosión, humo, volcán, tormenta, rojo. Una vez que se alcanza el registro agudo, sobre un $f f$, el fenómeno puede invertirse: la terminación se prepara mientras el Cristal Baschet (compás 34) desgrana regularmente el motivo de la segunda pieza, Agua.

La última pieza, Aire, está escrita sin compás de mensura; en ella se instalan estratos de sonidos obtenidos mediante botellas de "sonido neto" y de "sonido de viento" (sobre un modo simétrico de alturas); se insertan eventos irregulares que crean un desorden aleatorio mediante el juego de la flauta, que extrae sus sonidos de los reservorios de notas, así como del enunciado de palabras, de jirones de frases, inicialmente susurradas ("Multicolor como un globo en la noche" [...]; "se arremolina... cada vez más rápido; como un huracán... en 
el medio"...), que proliferan hasta el clímax (ff, letra B). El proceso puede ahora invertirse hasta el silencio. En la letra $\mathrm{C}$, una peroración hace intervenir diversos llamadores de ornitología permitiendo aún la subsistencia de palabras y sonidos de la flauta hasta "cada vez menos sonidos".

II. El pensamiento de François-Bernard Mâche (1935) puede servirnos de guía en el intento de formular una aproximación Bachelardiana de la música: él es autor de numerosas obras y artículos. Sus obras pueden abordarse como una aplicación de sus propias teorías, pero ellas representan ante todo la intuición de otra manera de hacer y pensar la música: una manera de aprehender y de comprender un mundo sonoro desprovisto de una vocación humanista. El siglo XX estaría atravesado por tres tendencias principales: la influencia de modos de pensar científicos; la nostalgia de un código universal; el resurgimiento de lo sagrado (Mâche, 1983, p. 54.). Más tarde en 1987, François-Bernard Mâche (Ibíd.) resume esas tres orientaciones en dos grandes elecciones estéticas: la retórica, por una parte, y lo instantáneo por otra, reuniendo así las dos primeras tendencias en una sola.

La retórica, significa la perpetuación de un modelo discursivo que, a través de diversos avatares, se remonta al siglo XVII. [...] Se trata de prolongar lo esencial, esto es el culto de un modelo lingüístico con sus niveles jerárquicos. El otro polo estético es aquel de lo instantáneo. El "material" sonoro pierde su neutralidad, se colorea al infinito; la música viene a ser menos una lógica, y más una aventura. Desde Debussy, ha sido Varèse quien, prácticamente solo, defiende la verdadera modernidad, ya que él descubre la naturaleza sonora de una "inteligencia latente". Sin querer oponer estas dos orientaciones, de un lado una música de notas y, del otro, una música de sonidos, es posible constatar una tensión entre estos dos polos que se va a ejercer muy claramente a lo largo del siglo XX, y a veces aún dentro de una misma obra. Aquello que ya no puede o no quiere entrar dentro de las estructuras del orden, es el timbre, que no estando sujeto a la altura, va a revelar su fuerza al mismo tiempo subversiva y liberadora, y su anclaje en "los sonidos del biotopos", según la expresión del compositor. Pensamos aquí en las experiencias de quienes han trabajado con el ruido, y en las músicas electroacústicas; cuando comenzó a trabajar en el Estudio de Fonología de Milán, Bruno Maderna hablaba de cambios de metabolismo, al descubrir la múltiples posibilidades que ofrecía ese nuevo medio: lo aún nunca escuchado al alcance de la mano, mediante el juego de las manipulaciones. La "estética de lo instantáneo" es escucha aún antes de ser experimentación; es una manera de soltar la presa, como si el compositor aceptara y percibiera la medida de lo que no puede ser dominado por él. O, de manera más simple, como si el compositor, al abrirse al mundo sonoro, soltara la prenda de su rol o de su propia función de compositor, haciéndose en adelante un simple mediador, un escucha privilegiado.

Así pues, la poética que aquí esbozo reposa sobre un postulado monista que afirma por partida doble la unidad del universo: como una sonósfera externa en la que los ruidos y las músicas se entrecruzan, se intercambian, se hibridan sin detenerse ante las aduanas culturales y, en ocasiones, ni siquiera ante los límites de las especies; como una legislación interna, única y dúctil, que rige de manera oblicua todas las señales sonoras, por lo menos aquellas de los seres vivos. Se encuentran de nuevo los dos aspectos de la naturaleza, como resultado y como principio, en un modelo que ambiciona regresar a los inicios a partir del contacto sensorial con los fenómenos (Mâche, 1983, p. 113-114.).

Schoenberg hace de la altura una dimensión del timbre, en la última página de su Tratado de Armonía, mientras que Daniel Charles, siguiendo el hilo y extrapolando la referencia Shoenbergiana, hace de la voz-lenguaje una dimensión de la voz-timbre (Charles, D. 1978, p. 44). Así mismo, en una última etapa que religaría y subsumiría las dos primeras referencias, François-Bernard Mâche (1972) hace del pensamiento racional una dimensión del pensamiento latente, es decir, del pensamiento mítico. De esta manera, vendría a ser función del compositor, intermediario entre "la substancia musical del universo y un público que debe ser descondicionado", la de traducir lo "mítico en cultural", para reactivar y dar a escuchar las "imágenes sonoras que surgen del inconsciente, y que pueden ora fijarse en clichés, ora actuar como arquetipos capaces de animar invenciones personales".

La convicción de que lo real (en este caso el mundo de los ruidos en estado bruto: elementos, voces animales y humanas, máquinas, instrumentos de música...) es -tanto en el dominio sonoro como en el de lo visible- más rico que todas las combinaciones imaginables a priori, conduce a remitir a un rango auxiliar la lógica racional (contrapuntística, serial, estocástica u otra), así como a asignar al músico como tarea principal la de extraer de esta realidad, que ha venido a ser explotable gracias al magnetófono, un pensamiento latente (Ibíd., p. 118.).

La obra de Mâche se despliega alrededor del concepto naturalista según diferentes modalidades, desde la imitación hasta la adopción del estado del referente o del modelo sonoro - diferentes gradaciones que Marta Grabocz ha presentado y analizado minuciosamente ${ }^{1}$. Pero el objetivo (la utopía), y allí radica la singularidad de la propuesta del compositor, consiste en la puesta en evidencia de la existencia de ciertos arquetipos universales que la música tiene el poder de revelar. Se postula así la identidad fundamental de ciertas estructuras formales, presentes tanto en la naturaleza como entre los animales y 
los hombres; la indagación y el reconocimiento de trazos comunes entre civilizaciones alejadas es uno de los aspectos de esta búsqueda, que es tanto musical como antropológica y etnológica.

Desde Debussy existe una ruta precisa: la creación musical podría ser en esencia el encuentro entre los arquetipos y una fenomenología del mundo sonoro, entre lo innato y lo percibido. Esta puesta entre paréntesis de lo cultural no podría sin duda ser total ni definitiva, pero no es en este aspecto donde hay que trabajar, ya sea para progresar o para regresar (Machê, 1983, p. 60).

III. El pensamiento de Gaston Bachelard, por otra parte, puede alimentar una reflexión sobre el proceso de creación musical, tal como se manifiesta en los albores del siglo XX. Nos permite aprehender lo que haya podido surgir en la música -la de Debussy en particular- como emblemático de una relación con la naturaleza en su sustancialidad reencontrada. Movimiento que François-Bernard Mâche califica como "regreso de lo reprimido" -en el sentido sicoanalítico del término- y que viene a ser no un proceso nuevo en sí mismo, sino algo que se descubre y devela de nuevo. La creación artística y musical se inscribe dentro de un proceso general de cambio de paradigmas en la cultura europea.

El filósofo consagra uno de sus primeros estudios a la ensoñación, entrecruzamiento entre el psicoanálisis Freudiano, el romanticismo alemán y los aportes de Jung. Los estudios Freudianos han puesto al día los mecanismos inconscientes, que pueden ser accesibles a través del sueño, y demostrado el poder de la represión (verdrängung); Bachelard (1949), contrario sensu, demuestra la fuerza positiva de la ensoñación, sueño despierto que, hundiendo también sus raíces en el subconsciente, expresa y despliega la imaginación.

A nuestro parecer, esta ensoñación es extremadamente distinta del sueño por el hecho mismo de estar siempre más o menos centrada en un objeto. El sueño camina de manera lineal, olvidando su camino al correr. La ensoñación opera en forma de estrella: regresa a su centro para desde allí lanzar nuevos rayos (Bachelard, 1949, p. 36). ${ }^{2}$

Bachelard, en sus obras sobre los elementos, no dejará de "exaltar, según la expresión de Jean Libis (2007, p.90), las fantasías sobre la ensoñación”, y de incitar a la ensoñación. La ensoñación bebe de las fuentes de los cuatro elementos arquetípicos de la materia, que son "reservas de entusiasmo, [...] que nos ayudan a creer en el mundo, a amar el mundo, a crear nuestro mundo"; "cada arquetipo es una abertura hacia el mundo, una invitación al mundo. De cada abertura se proyecta un ensueño que impulsa" (Bachelard, 2011, p. 107).
La imaginación material, esta sorprendente necesidad de "penetración" [...] va a pensar la materia, a soñar la materia, a vivir en la materia, o bien -lo que viene a ser lo mismo- a materializar lo imaginario. Hemos creído bien fundado hablar de una ley de las cuatro imaginaciones materiales, ley que atribuye necesariamente a una imaginación creadora, uno de los cuatro elementos: fuego, tierra, aire y agua (Ibíd. p. 13).

De este modo, a partir del arquetipo, imagen primordial o "gran imagen", se inserta en el andamiaje toda una "floración de imágenes isomorfas" (Ibíd., p. 56) movidas por un dinamismo específico, un "tonus generalis", el "impulso humanizante" (Bachelard, 1943 p.18) ${ }^{3}$. "Hormonas de la imaginación, [los elementos] ponen en acción grupos de imágenes. Estos ayudan a la asimilación íntima de lo real disperso en sus formas. Es por ellos que son llevadas a cabo las grandes síntesis que dan caracteres más o menos regulares a lo imaginario" (Ibíd., p.19). Esta búsqueda de "leyes idealísticas" que Bachelard intenta emprender (Ibíd., p. 12-22) acerca de las actividades de la imaginación, se apoya en una terminología precisa. Se trata de determinar "la filiación regular de lo real a lo imaginario" (p.13).

Es a los objetos, a las diferentes materias, a los "elementos", que preguntaremos a la vez su densidad específica de ser y su energía exacta de devenir. A los fenómenos, les pediremos consejos de transformación, lecciones de mutabilidad sustancial, en suma, una física detallada de la imaginación dinámica (Ibíd., p. 16).

En la Poética de la ensoñación, después de todo un recorrido y de la escritura de su serie sobre los cuatro elementos, Bachelard vuelve de nuevo sus pasos sobre la ensoñación, descargándola de todo método de investigación. Hay allí un acto de soltar prenda de la voluntad de control y de organización de lo imaginario: la ensoñación se hace cósmica: ella es estado, contemplación, y opera una fusión con la naturaleza. Es una disposición psíquica.

Las ensoñaciones cósmicas nos separan de las ensoñaciones de proyectos. Ellas nos sitúan en un mundo, y no en una sociedad. Hay una suerte de estabilidad, de tranquilidad, que le pertenece a la ensoñación cósmica. Ella nos ayuda a escapar del tiempo. Es un estado (Bachelard, 2011, p.19). [...] Pero el soñador de mundo no mira el mundo como un objeto, no tiene nada que ver con la agresividad de la mirada penetrante. Él es sujeto que contempla (Ibíd., p.159).

Bachelard esboza, según Jean-Jacques Wunenberg, una poética ecológica que no deja de recordar el enfoque de un Murray Schafer y su noción de soundscape (paisaje sonoro), o ciertas músicas de las que el ejemplo más elocuente serían las Presque rien de Luc Ferrari (o aún las Cuatro fonografías de Mâche). El paisaje sonoro es una disposición, una postura de escucha. El compositor (si el término puede todavía tener alguna validez) está allí para hacer escuchar, ya no existe la ocupación de un territorio sonoro por una música creada para ese efecto, sino el desvelamiento de un espacio sonoro. Basta con situar el micrófono, pero esta simple operación puede resultar delicada: ese gesto ha sido precedido por una escucha paciente. 
[La poética ecológica] implica una especie de geo-patía, una cierta capacidad de participar de la materia, de sentir un medio-paisaje, de "con-sentir" con un lugar, de vibrar con él, de descender por las imágenes hasta sus profundidades [...] Es la razón de que las actividades humanas creadoras frecuentemente reposen sobre una interiorización de los ritmos de las materias y de los paisajes (en el sentido espacial y temporal del descubrimiento de los intervalos entre las formas) y sobre una exteriorización de los ritmos corporales en el mundo exterior (Wunenburger, p. 85).

"La materia ya no es entonces fuente de una representación, escindida de su sustancialidad, sino que ella autoriza una participación activa real que acaba por disolver los límites del sujeto y del objeto" (Ibíd).

Finalmente, está la fuerza de arquetipo de la infancia, "el arquetipo de la felicidad simple", "el gran arquetipo de la vida que comienza" (Bachelard, 2011) ${ }^{5}$, que engloba y subsume todos los arquetipos de la materia.

Todas las infancias son las mismas: infancia del hombre, infancia del mundo, infancia del fuego, otras tantas vidas que no fluyen siguiendo el hilo de una historia. El cosmos del soñador nos sitúa en un tiempo inmóvil, nos ayuda a fundirnos con el mundo (Ibíd., p.166).

Como subraya Jean Libis, "Bachelard hace el elogio del carácter ahistórico de todos los comienzos" (Libis, 2007, p. 157)6, y "el soñador se desliza en el bienestar original del mundo [...] en esa ausencia de temporalidad que constituye el universo de la infancia".

Ciertos aspectos del pensamiento de Bachelard entran en resonancia con "la estética de lo instantáneo" tal como la formula Mâche, y permiten plantear los primeros lineamientos de una estética Bachelardiana de la música. El filósofo reivindica un vínculo particular con la naturaleza que encuentra su realización en una forma de fusión, y de la que la disposición mental más propicia sería el sueño despierto. El despliegue de imágenes a partir de una imagen fundamental inconsciente (arquetipo), siguiendo un continuum, respondería a una lógica de formación de la imaginación creadora; la última etapa de esta ascensión vendría a ser la creación artística (literaria para Bachelard) que se inscribe en una "determinación vertical": sería el devenir del hombre acceder al estadio creativo, estadio de supra-consciencia, de agudeza activada, nutrida por la ensoñación, ella misma alimentada a su vez por los arquetipos. La lógica que Bachelard deseaba establecer parece ceder, con el paso de sus obras, a un estado de apertura, de disponibilidad. En el proceso pueden encontrarse trazos del pensamiento de Heidegger, pero también de ciertos místicos. La "verticalización”, creada por el nicho y la apertura de la ensoñación, reúne el espacio y el tiempo, el hombre y la naturaleza. Allí éste se encuentra sereno, en una plenitud en que el ego se diluye.

La ensoñación poética nos ofrece el mundo de los mundos. Ella es la puerta de entrada a un mundo hermoso, a mundos hermosos. Ofrece al yo un no-yo que es el bien del yo: mi propio no-yo mío. Es ese no-yo mío lo que encanta al yo del soñador y que los poetas saben hacernos compartir. Para mi yo soñador, es ese no-yo mío lo que me permite vivir con la confianza para estar en el mundo (Bachelard, 2011, p.12).

Dicho de otra manera, la ensoñación es la palabra maestra: ella es estado, proceso/movimiento y acceso a la creación. Queda la dimensión sonora, la dimensión de lo oído, de lo escuchado, que Bachelard no evoca, o lo hace muy poco. Lo real es igualmente sonoro.

IV. "Cada arte reclama una fenomenología específica” (Ibíd., p.157), postula Gaston Bachelard. François-Bernard Mâche, en su obra Música en singular (2001), continuando su reflexión sobre "la permanencia de una dimensión natural de la actividad musical" (Mâche, 2001, p. 12.), y en un contexto de mundialización galopante y mestizaje generalizado, postula la existencia de arquetipos musicales universales y comienza a formular su inventario. El arquetipo, como él lo define con justeza, "designa un principio organizador naturalmente activo en el psiquismo": éste puede ser abordado dentro de un marco psicoanalítico, Jungiano en particular, donde manifiesta su fuerza dentro del inconsciente individual o colectivo; o puede ser analizado dentro de un marco neurobiológico o cognitivista (Ibíd. p. 33 et ss). Su aproximación requiere, en todo caso, de una combinación de saberes y de la multidisciplinaridad. Así mismo se reivindica hoy una musicología comparada, sobrepasando el eurocentrismo de los estudios iniciales. Si bien es cierto que Bachelard no figura en las referencias del musicólogo-compositor, Jung y Durand ocupan en cambio un buen espacio allí. 
Los arquetipos fundamentales se sitúan al nivel más primordial, "imagen flotante dentro del inconsciente", mientras los enunciados musicales lo hacen al nivel de las estructuras de superficie. Puede ser así legítimamente formulada la cuestión de querer aislar arquetipos musicales.

Pero buscar arquetipos bajo sus manifestaciones sonoras no prohíbe, en último caso, identificarlos ulteriormente como aún más universales que sus solas encarnaciones musicales. Dicho de otra manera, aunque los esquemas dinámicos que se encuentran más o menos en todas partes en el origen de las formas sonoras análogas no limitan su acción a la música, y pertenecen al más amplio nivel del mito, puede ser suficiente para el musicólogo, en un primer momento, identificarlos dentro de su propio dominio, para luego pasar eventualmente el relevo al psicólogo, al filósofo, o a cualquier otro investigador de lo universal (Ibíd. p. 34).

La búsqueda e identificación de arquetipos a priori musicales procede, por etapas intermedias y sucesivas, desde una línea de cresta hasta llegar a la inmersión en el arquetipo. Las etapas se establecen por la identificación primero de fenotipos, luego de genotipos. El análisis distributivo sincrónico aísla los fenotipos, mientras el análisis distributivo diacrónico aísla los genotipos. El análisis distributivo consiste en la elaboración de una serie de elementos discretos, sobre la cual pueden operarse reagrupamientos, que pueden a su vez ofrecer diversas combinaciones: el principio consiste en dotar de coherencia a la cadena, neutra en un primer momento, proponiendo variantes e invariantes, y/o aislando elementos constitutivos. Los genotipos son la rotulación de similitudes entre las cadenas. La búsqueda de arquetipos, etapa siguiente, procede siempre según un esquema arborescente (desde la línea de cresta).

Del arquetipo a la música, el movimiento ascendente traza la emergencia de la imaginación creadora a partir de un nivel psíquico que participa aún del instinto. Hay allí entonces, por hipótesis, continuidad y no ruptura de lo natural a lo cultural (Ibíd. p.261).

Mâche ha enumerado cuatro arquetipos musicales: el ostinato, el acelerando, el responso (o eco), la re-exposición (o repetición diferida); "todos representando de manera más o menos aparente formas de repetición" (Ibíd. p. 41).

V. Es posible intentar el entrecruzamiento de las dos aproximaciones: la de Bachelard y la de Mâche. Tanto según el filósofo como el compositor, toda obra es, en efecto, alimentada por una imagen "fundamental", "primordial". La ruta de Mâche proporciona una conexión directa con el pensamiento de Bachelard, es una aplicación musical del mismo. Las etapas intermedias, definidas por el compositor como fenotipos y genotipos, se identifican por medio del análisis distributivo. No abordaremos la música de Sophie Lacaze por medio de este método, que tiene de musicología comparada. Nos inspiraremos en cambio en la elección de un recorrido vertical: todo actúa o es agitado a lo largo de un continuum desde las imágenes más primitivas, profundamente inconscientes. Nuestra búsqueda no será comparativa sino en la medida en que pueda develar trazos comunes entre las cuatro piezas.

Mientras para Bachelard la forma más lograda está representada por la creación poética, Mâche demuestra toda la fuerza y el dinamismo ascensional de la creación musical, según un continuum de esencia puramente musical.
La obra de Sophie Lacaze se nutre de figuraciones vinculadas con la evocación de los cuatro elementos, pero también de estructuras, de formas que tienen de la estética de lo instantáneo. En ella se dan a escuchar, en fin, lo que podríamos llamar estados de la materia sonora. Las referencias a los elementos por medio de la imitación, la sugerencia, la descripción en la música, constituyen un primer nivel. Pero la música, recordémoslo, es cosa mentale, o dicho de otro modo, entre el imaginario del compositor y la percepción en que se ve comprometido el oyente, hay discrepancias (es la merced concedida a la obra de arte).

Tierra: yo he querido sugerir musicalmente la creación del mundo, o al menos una cierta idea de la creación del mundo, con la aparición de la vida animal. La flauta bajo y los sonidos graves evocan la oscuridad y las profundidades de la tierra; los ritmos y la escansión de fonemas por los niños son encantamientos para los dioses. La flauta asciende poco a poco, y cuando llega al agudo, sucede la aparición de la vida animal: reptiles, dinosaurios, mamíferos, y finalmente, los canguros, animales emblemáticos de Australia, uno de los más antiguos continentes del mundo. Vida = soplo, la flauta termina la pieza con sonidos eólicos.

Agua: el cristal Baschet sugiere la pureza y la limpidez del agua, y textos poéticos evocan el agua. Unas aguas tranquilas.

Fuego: en esta pieza, la flauta asciende en staccato y pizzicato -sugiere las llamas que se elevan. Los niños imitan los chasquidos del fuego con plástico de burbujas y otros pequeños instrumentos, y proyectan sonidos o palabras en relación con el fuego. Cuando éste alcanza su paroxismo, el cristal Baschet reaparece con el tema del agua, y se extingue lentamente.

Aire: allí hago uso principalmente del soplo, por medio de la flauta y de botellas afinadas. Dado que había acudido antes a un haiku del príncipe Shotoku para el Agua, le he pedido a los niños que escribieran haikus, de los que he hecho luego mesósticos (como John Cage en Roaratorio), sobre las palabras tierra, agua, fuego y aire. Hacia el final, los textos hablan de la naturaleza y la flauta los ilustra libremente.

Esto constituye un primer nivel, de superficie, un nivel de comprensión de la materia y de los movimientos sonoros/musicales, que se nutre de una dimensión narrativa. Nos ha hecho el relato de la creación del mundo, la fluidez y los movimientos del agua, la vida del fuego, los torbellinos del aire, y en una suerte de coda general, los ruidos y murmullos de la naturaleza que se alejan poco a poco, se funden y se interiorizan en nuestro 
oído, siendo imposible una clausura. Esta opción narrativa o lineal se ve subrayada por las palabras, los fragmentos de frases y de poemas que orientan la escucha.

Se emplean dos tipos de estructuras, la forma en arco o palindrómica que caracteriza las piezas Tierra, Fuego y Aire, y la forma estática que caracteriza Agua. Estas dos formas presentan similitudes estructurales: se plantea un material sonoro de partida, que va a auto-generarse. Ellas están sostenidas por tipos de escritura: el ostinato, la escansión iterativa y expansiva alrededor de una nota pivote, la escritura aleatoria en reservorios, y el bordón o estasis.

-El ostinato rítmico de Tierra es seguido por su expansión dinámica. El núcleo sonoro elegido no sufre transformación o desfasamiento alguno de sus valores: se circunscribe a repetir de manera ob stinada, es la adición progresiva de elementos sobre esta materia primera, así como la intrusión gradual de la expansión (densidad e intensidad crecientes de elementos), lo que constituye la pieza Tierra. El ostinato melódico-rítmico de la segunda pieza Agua permanece en el estado, es la estasis. En los matices $p$ y mp y en un movimiento lento se enuncian fragmentos de poemas, que se insertan sobre el ostinato inicial. La primera pieza no ofrece indicación alguna de orden semántico: las onomatopeyas participan de la escansión general, haciéndose cargo de un sistema de acentuación suplementario; basta con leer la partitura o las indicaciones dadas por la compositora para saber que se trata de la creación del mundo. La mención de animales saliendo del agua induce microeventos en la materia sonora, en una suerte de estremecimiento, de agitación ligera. La segunda pieza abre un campo semántico sobre el agua, pero éste queda en suspenso, siendo atrapado en la red obsesiva del ostinato (también de su doble, en canon): están allí palabras para apenas degustarlas, sin que alguna significación se les adhiera realmente.

-La segunda figura o tipo de escritura notable, es la escansión iterativa y expansiva alrededor de una nota pivote. Aparece en dos ocasiones. La pieza Fuego es alimentada exclusivamente por este elemento. Elemento obsesivo, especie de perpetuum mobile, repetido primero y luego ornamentado, gana por círculos concéntricos todo el espacio sonoro, es agitado por un movimiento giratorio y ascendente. El mismo procedimiento es empleado en Tierra: la flauta bajo participa en la expansión de la materia sonora fundada sobre un ostinato, imprimiendo un movimiento giratorio y obsesivo. Y es la superposición de esos dos trazos de escritura lo que engendra la dinámica expansiva y general de toda esta primera pieza.

-La tercera figura está constituida por una escritura aleatoria en reservorios de notas o de palabras. El reservorio, al contener sólo un número limitado de elementos, marca también un carácter obsesivo. Su utilización es fecunda en las dos últimas piezas. En
Fuego, los reservorios se insertan sobre el movimiento ascensional de la flauta (entradas sucesivas de los coros de niños 1,2 y 3): onomatopeyas, luego fonemas, sílabas y finalmente palabras, son atrapadas dentro de la curva general en forma de arco. Esta escritura aleatoria crea un rumor verbal/sonoro, realzado por los "ruidos del fuego (plástico de burbujas y pequeños instrumentos que evocan el crepitar del fuego)". La última pieza está fundada sobre este tipo de escritura: flauta, voces y botellas. Señalemos que en la parte B, el reservorio de la flauta está constituido por 8 notas que retoman el carácter obsesivo y expansivo del segundo tipo de escritura. En suma, dos tipos de escritura se conjugan: la escritura aleatoria en reservorios y la escansión iterativa y expansiva.

-El último tipo de escritura es el bordón o drone. La peroración de la segunda pieza Agua instala una superficie estática formada por los tres coros de niños y la flauta alto, alrededor de la nota re, sometida a ligeras fluctuaciones de alturas, de dinámicas y de granulación (trémolos de la flauta y glissando de vocales: entre $O$ y $A$ ). La última pieza Aire instala un drone, en las secciones A y B; formado por las botellas de sonido ventoso y de sonido neto, su materia, su granulación, es más espesa y sus fluctuaciones más importantes. Es de allí de donde surgirán y se formarán los primeros reservorios de la flauta y de las botellas de sonido neto. Tres figuras se conjugan allí: el reservorio, la escansión iterativa y expansiva, y el drone.

La repetición parece alcanzar todos los niveles de la escritura, del ostinato al drone. Una repetición llevada hasta el encantamiento que "trashuma" en el lugar mismo, y parece hacer retroceder o vacilar cualquier forma de clausura de la obra.

Los estados de la materia sonora remiten a lo que Daniel Charles designaba hace poco como "narratividades primeras" (Charles, op. cit., p. 99-110)7: "Aquello que el sonido relata" (Ibíd., p. 108); es la música la que debe hacer resonar, en un murmullo ininterrumpido, el rumor del mundo, el susurro mismo del alli hay" (p.110). La narratividad en música no puede venir, según Daniel Charles y retomando los postulados de L.B. Meyer, sino del exterior, "de una temporalidad venida de otra parte"-muy exactamente del lenguaje, o del relato, del argumento, del programa, etc." (Ibíd.). Puede decirse que la música de Sophie Lacaze es también escucha de un drone (de ese rumor fundamental) que ella reactiva, fabrica, remodela, y de la que ella ejerce las ocurrencias en diversos tipos de escritura. Éstos no avanzan en absoluto, no responden a proceso alguno (o si en algo, es solamente sobre la línea de cresta que es narratividad de superficie). Tampoco se consuman en forma alguna, o más precisamente, no cesan de consumarse (el rojo enrojece). Así pues, hay drone por todas partes, en el sub-basamento, y en lo que "verticaliza". Al hacerlo se despliega en dos formas (cuasi-arcaicas): aquella en arco (con inflamiento en "su centro" del tejido sonoro), y la otra estática (repitiendo indefinidamente el mismo sonido) en "un relato/recital/recitativo de timbres" (Ibíd. p. 107).

El drone, en respuesta, en resonancia con la ensoñación Bachelardiana, es sonido-maestro, sonido-amo: es estado, proceso/movimiento, y acceso a la formulación musical:

Un único sonido no es jamás estacionario: por el contrario, aparece como repitiéndose indefinidamente a sí mismo, pero sin que esta repetición conduzca jamás a lo idéntico; [...], lo que se deja presentir es la irrupción no de un metro midiendo, sino de una vaga métrica de despliegue indefinido, incalculable, oceánico. [...] Un sonido no muere a menos que otro lo sustituya; el mismo sonido puede morir indefinidamente mientras es paulatinamente reemplazado por otro sonido que no es otro que él mismo y sin embargo "llena" el vacío que deja su retirada. De allí se desprende que la escucha de un solo sonido es ya una escucha del tiempo. Resonar, para un sonido, es abrir un espacio de tiempo (Charles, 1984). 
No hablaremos de desdoblamiento en las obras de Sophie Lacaze, al modo de Daniel Durney en su presentación de la música de Mâche (estábamos en los años 1990 y en una aproximación todavía dialéctica de la música). Toda la música de Sophie Lacaze parece estructurar su andamiaje a partir de los Cuatro elementos, como una imagen primordial, un drone. A partir de ese punto, un mar, podría decirse, que no deja de moverse, todas las piezas pueden ser leídas, desplegadas, o si se quiere, encadenadas. Finalmente, el empleo artesanal de pequeños instrumentos no inventariados o aun del cristal Baschet, instrumento de factura así mismo acuática, que se despliega en la segunda pieza Agua, confieren a la obra, aparte una carga simbólica, una dimensión del hacer, del fabricar. Y les corresponde a los niños trabajar la misma materia sonora y musical, inventarla, soñarla.

Notas

${ }^{1}$ Dirigimos al lector a dos autores, Marta Grabocz : « La poétique de F.-B. Mâche ( $1^{\text {ère }}$ partie) » et. « Esquisse typologique des macrostructures ( $2^{\text {ème }}$ partie) » et Daniel Durney : "La musique et don double » in Les Cahiers du CIREM n 22-23, François-Bernard Mâche, Décembre 1191 - Mars 1992, p. 118-132 et p. 133-170.

${ }^{2}$ Se trata aquí de la ensoñación ante el fuego, pero que puede ser aplicada a los otros elementos. Para las referencias a Freud y el psicoanálisis, nos remitimos a la obra de Jean-Jacques Wunenburger, Gaston Bachelard, poétique des images, Mimesis, L'oeil et l'esprit, Paris, 2012

${ }^{3}$ Términos empleados para la imaginación aérea, pero que pueden aplicarse a los otros elementos.

${ }^{4}$ Cf. su obra de referencia: The Soundscape, our sonic environment and the tuning of the world, publicadaen 1977.

${ }^{5}$ Expresiones que se encuentran en las páginas 106-107.

${ }^{6}$ Retomamos la cita de Bachelard que Jean Libis comenta ampliamente.

7 Cf. el texto de Daniel Charles, maravillosamente inspirado e inspirador: " Musique et narrativité : L'écriture du bruit ", en La fiction de la postmodernité selon l'esprit de la musique, op. cit., p. 99-110.

\section{Referencias bibliográficas}

Bachelard, G. (1943) L'Air et les Songes, Essai sur l'imagination du mouvement, Paris : Librairie José Corti

Bachelard G. (1949) La psychanalyse du feu, Paris : Editions Gallimard

Bachelard, G. (2011) La poétique de la rêverie, Francia : Quadrige.

Charles, D. (1978) Le temps de la voix, Francia: Editions Universitaires, Jean-Pierre Delarge.

Charles, D. (1984) Le son comme image du temps, Images (7)

Charles, D. (2001) La fiction de la postmodernité selon l'esprit de la musique, Francia: Presses universitaires de France.

Grenier, J. (1948) Prière à la nature, in Entretiens sur le bon usage de la liberté, Paris: Gallimard.

Lacaze, S. (2005) Les quatre éléments, Danmark: edition Svitzer

Libis, J. (2007) Gaston Bachelard ou la solitude inspirée, Berg International éditeurs.

Mâche, F.B. (1972) La création musicale aujourd'hui, Neuchâtel : UNESCO et la Baconnière, p. 118.

Mâche F.B. (1983) Musique, Mythe, Nature ou les dauphins d'Arion, Klincksieck et Cie : Librairie des Méridiens

Mâche, F.B(2001) Musique au singulier, Francia : Editions Odile Jacob.

Wunenburger, J.J. (2012)Gaston Bachelard, poétique des images, Francia : Mimesis Edizioni

\section{Geneviève, Paule MATHON:}

Maestra de conferencias extraclase, Université Paris-Est Marne-la-Vallée, actualmente es investigadora de la misma universidad.

E. mail : genevieve.mathon@noos.fr - genevieve. mathon@univ-mlv.fr

Artículo recibido en septiembre de 2013 y aceptado en enero de 2014 